\title{
Multiple Resistance Traits Control Plum pox virus Infection in Arabidopsis thaliana
}

\author{
V. Decroocq, ${ }^{1}$ O. Sicard,, J. M. Alamillo, ${ }^{2}$ M. Lansac, ${ }^{1}$ J. P. Eyquard, ${ }^{3}$ J. A. García, ${ }^{1}$ T. Candresse, ${ }^{1}$ \\ O. Le Gall, ${ }^{1}$ and F. Revers ${ }^{1}$ \\ ${ }^{1}$ UMR GDPP INRA-Université Victor Segalen Bordeaux 2, BP81, 33883 Villenave d'Ornon Cedex, France; ${ }^{2} \mathrm{CNB}-\mathrm{CSIC}$, \\ 28049 Madrid, Spain; ${ }^{3}$ U.R.E.F.V., INRA, BP81, 33883 Villenave d'Ornon Cedex, France
}

Submitted 2 August 2005. Accepted 12 January 2006.

\begin{abstract}
Twelve Arabidopsis accessions were challenged with Plum pox potyvirus (PPV) isolates representative of the four PPV strains. Each accession supported local and systemic infection by at least some of the PPV isolates, but high variability was observed in the behavior of the five PPV isolates or the 12 Arabidopsis accessions. Resistance to local infection or long-distance movement occurred in about $40 \%$ of all the accession-isolate combinations analyzed. Except for Nd-1, all accessions showed resistance to local infection by PPV-SoC; in the Landsberg erecta (Ler) accession, this resistance was compromised by sgt1 and rarl mutations, suggesting that it could be controlled by an $R$ gene-mediated resistance pathway. While most of the susceptible accessions were symptomless, PPV induced severe symptoms on inflorescences in C24, Ler, and Bay-0 as early as 15 days after inoculation. Genetic analyses indicated that these interaction phenotypes are controlled by different genetic systems. The restriction of long-distance movement of PPV-El Amar and of another member of genus Potyvirus, Lettuce mosaic virus, in Col-0 requires the $R T M$ genes, indicating for the first time that the RTM system may provide a broad range, potyvirus-specific protection against systemic infection. The restriction to PPVPS long-distance movement in Cvi-1 is controlled by a single recessive gene, designated $r p v 1$, which was mapped to chromosome 1. The nuclear inclusion polymerase b-capsid protein region of the viral genome appears to be responsible for the ability of PPV-R to overcome rpv1-mediated resistance.
\end{abstract}

Additional keyword: Sharka.

Sharka disease is the major limiting factor in stone fruit tree production in Europe and North America. It is caused by Plum pox potyvirus (PPV) and is one of the most serious viral diseases in peach, apricot, and plum orchards. Losses from Sharka are due primarily to precocious fruit drop and decreases in fruit quality. The potential of PPV to severely affect the fruit tree industry has prompted the European Union to classify it as a quarantine pathogen (European Union council directive 2000/ 29/EEC, annex II), while the United States federal government has classified it as one of the top ten significant threats to U.S. agriculture (Public Health Security and Bioterrorism Act of

Corresponding author: Véronique Decroocq;

E-mail: decroocq@bordeaux.inra.fr

* The $\boldsymbol{e}$-Xtra logo stands for "electronic extra" and indicates the HTML abstract available on-line contains supplemental material not included in the print edition. A table lists the twelve Arabidopsis accessions and the five PPV isolates used in this study and Figure 1 appears in color online.
2002, PPV belongs to the family Potyviridae. Apart from the atypical El Amar (EA) isolate (Wetzel et al. 1991a) and the sweet and sour cherry-infecting isolates (Crescenzi et al. 1997; Nemchinov and Hadidi 1996), most PPV isolates are classified into two major strains, $\mathrm{M}$ (from the isolate Marcus) and D (from the isolate Dideron) (Candresse et al. 1998). Recently, a new atypical strain, W3174, was discovered, but its origin is still unclear (James and Varga 2005).

Studies of the molecular mechanisms underlying the interactions of PPV with its woody hosts have been hampered by the difficulties inherent to the molecular genetic analysis of stonefruit tree species, in particular the extended generation times and the length and space requirements of phenotypic tests. Four years of monitoring after inoculation are needed to assess the level of resistance or susceptibility of a given Prunus cultivar. Standardization of the resistance tests has similarly proved difficult because of delayed responses to inoculation, variability of the virus, physiological state of the host plant, and inoculation method.

In the past few years, the genetic and molecular advantages of model plant Arabidopsis thaliana were exploited for the identification of host factors contributing to virus infection. For example, two genes, Tobamovirus multiplication 1 and Tobamovirus multiplication 3 (Tom1, Tom3), were identified from a screen for $A$. thaliana mutants that show defective infection by Tobacco mosaic virus (TMV) (Yamanaka et al. 2000, 2002). Both Toml and Tom3 are putative transmembrane proteins that may serve as membrane anchors for the TMV replication complex. Similarly, movement-defective mutants and the corresponding RTM loci, which cooperate to restrict Tobacco etch virus (TEV) long-distance movement, were described (Mahajan et al. 1998; Whitham et al. 1999). RTM1 encodes a jacalin-like protein, RTM2 shows homology to the plant small heat-shock proteins with a predicted transmembrane domain (Chisholm et al. 2000; Whitham et al. 2000), and an additional RTM loci has been identified but not yet fully characterized. The mechanism whereby the three RTM loci cooperate to restrict longdistance movement is still unclear.

Through studies of the interaction of eukaryotic translation initiation factors with viral proteins and genetic and reversegenetic analysis, eIF4E and eIF(iso)4E were linked to the potyvirus infectious cycle in various plant species (Duprat et al. 2002; Gao et al. 2004; Kang et al. 2005; Lellis et al. 2002; Nicaise et al. 2003; Ruffel et al. 2002; Stein et al. 2005). Our own analyses demonstrated a cosegregation of the Prunus $e I F($ iso) $4 E$ ortholog with a major quantitative trait locus (QTL) of resistance to sharka in peach and apricot (Decroocq et al. 2005). To identify new host factors involved in plant-potyvirus interactions, in particular with a potyvirus infecting perennial 
host plants, A. thaliana accessions were evaluated for their susceptibility to a range of PPV isolates representing a large part of the pathogen diversity.

Using this approach, we showed considerable variation in the susceptibility to PPV infection of $A$. thaliana accessions. Phenotypes ranging from complete invasion of the plant (accompanied or not by symptom-induction) to the inability of the virus to mount a productive replication in the initially inoculated leaves were observed and the genetic bases of some of these interaction phenotypes were analyzed.

\section{RESULTS}

Twelve Arabidopsis accessions of diverse geographical origin were inoculated with five isolates of PPV. Responses of Arabidopsis to PPV were classified as susceptible (referred to as $\mathrm{S}$ in Table 1) when the virus was detected in the uninoculated inflorescence tissues by enzyme-linked immunosorbent assay (ELISA) or by reverse transcriptase-polymerase chain reaction (RT-PCR). While in most cases, the infected plants remained asymptomatic, there were several accession-isolate combinations in which symptoms were observed, such as reduction of plant growth, chlorotic stems, cauline, and rosette leaves, severe inflorescence stunting, and distortion accompanied or not with curling of the cauline leaves (Fig. 1). In Table 1 , the severity of the observed symptoms is indicated by the number of + signs. Plants in which both ELISA and RT-PCR assays were negative for PPV detection in inflorescence tissues were noted as resistant. Based on the results of PPV detection by ELISA or RT-PCR in the inoculated leaves, resistance phenotypes were further separated in resistance to local infection ( $\mathrm{Ri}$, no virus detected in inoculated leaves) and resistance to long-distance movement (Rsys, virus detected in inoculated leaves but not on distal uninoculated tissues). In preliminary experiments, the plants classified as $\mathrm{Ri}$ were assayed for PPV accumulation at 30 days postinoculation (dpi), but no accumulation was detected, and therefore, sampling at such late stages of Arabidopsis development was not routinely continued and plants were sampled at 9 and 21 dpi.

\section{PPV is able to systemically infect Arabidopsis thaliana.}

Although the response of Arabidopsis accessions to the five PPV isolates varied, all 12 accessions studied were infected by at least one PPV isolate, with or without development of visible symptoms (Table 1). However, none of the PPV isolates tested was able to infect the AteIF(iso)4E-1 transposon-disrupted mutant line (Duprat et al. 2002), suggesting that eIF(iso)4E plays an essential role during PPV infection in A. thaliana, as already shown for other potyviruses (Duprat et al. 2002; Lellis et al. 2002). Remarkably, the PPV-SoC isolate was able to systemically infect all tested accessions, while infection of uninoculated tissues was never observed for the PPV-SoC isolate (Table 1). In fact, only the Nd-1 accession was able to support local replication of PPV-NAT isolate, while the virus was never detected in the inoculated leaves of any of the other accessions tested. Although Ri is often associated with a hypersensitive response characterized by localized cell death at the infection site, a local lesion response was not macroscopically observed in any of the experiments reported here (data not shown).

In a number of accession-isolate combinations, PPV was only detected (by ELISA or by RT-PCR) in the inoculated leaves, indicating that the virus was unable to spread in the uninoculated tissues. Such a phenotype was observed in most of the accessions inoculated with the PPV-EA isolate. Absence of any long-distance movement was also observed when Cvi-1 was inoculated with PPV-PS and when Shahdara and Kas-1 were infected with PPV-R (Table 1). In contrast, the C24 accession was highly susceptible to PPV infection and developed severe growth defects when infected with M, D, and EA PPV strains. Severe symptoms were also observed when the Landsberg erecta (Ler) accession was infected with the PPV-R isolate, and slightly less severe ones were observed when Bay-0 was infected either with the PPV-NAT or PS isolates (Table 1). Two to three weeks after inoculation, chlorosis was observed on distal uninoculated tissues, such as cauline leaves and inflorescences. During later stages of infection, the plants exhibited severe growth stunting and occasionally lethal necrosis (Fig. 1).

These results show that a high degree of variation exists in the outcome of Arabidopsis-PPV interactions and that, in a significant number of cases $(40 \%, 24$ out of 60 accession-isolate combinations), some form of resistance against viral infection was observed. The genetic bases of some of the phenotypes observed were then analyzed using either forward or reverse genetics strategies.

\section{Genetic basis of symptom development} in the Ler accession infected with PPV-R isolate.

Limited information on the genetic bases underlying symptom development in virus-plant pathosystems is available so

Table 1. Phenotypic variation of Arabidopsis-Plum pox potyvirus (PPV) interactions

\begin{tabular}{|c|c|c|c|c|c|}
\hline \multirow[b]{2}{*}{ Arabidopsis accessions } & \multicolumn{5}{|c|}{ PPV isolates ${ }^{\mathrm{a}}$} \\
\hline & NAT (D) & $\mathbf{R}(\mathbf{D})$ & PS (M) & SoC & EA \\
\hline $\mathrm{C} 24$ & S+++ & S+++ & $\mathrm{S}+++$ & $\mathrm{Ri}$ & S+++ \\
\hline Landsberg erecta (Ler) & $\mathrm{S}$ & $\mathrm{S}+++$ & $\mathrm{S}$ & $\mathrm{Ri}$ & $\mathrm{S}$ \\
\hline BayO & S++ & $\mathrm{S}$ & S++ & $\mathrm{Ri}$ & Rsys \\
\hline Col-0, Col-3, Col-5 & $\mathrm{S}$ & $\mathrm{S}+$ & $\mathrm{S}$ & $\mathrm{Ri}$ & Rsys \\
\hline Ws, Ws-2 & $\mathrm{S}$ & $\mathrm{S}$ & $\mathrm{S}$ & $\mathrm{Ri}$ & Rsys \\
\hline Cvi-1 & $\mathrm{S}$ & $\mathrm{S}$ & Rsys & $\mathrm{Ri}$ & $\mathrm{S}$ \\
\hline Kas-1, Shahdara & $\mathrm{S}$ & Rsys & $\mathrm{S}$ & $\mathrm{Ri}$ & Rsys \\
\hline Nd-1 & $\mathrm{S}$ & $\mathrm{S}$ & $\mathrm{S}$ & Rsys & Rsys \\
\hline \multicolumn{6}{|c|}{ Arabidopsis mutants in Col-0 background ${ }^{\mathrm{b}}$} \\
\hline AteIF(iso) $4 E-1$ & $\mathrm{Ri}$ & $\mathrm{Ri}$ & $\mathrm{Ri}$ & $\mathrm{Ri}$ & $\mathrm{Ri}$ \\
\hline \multicolumn{6}{|c|}{ Arabidopsis mutants in Ler background ${ }^{\mathrm{c}}$} \\
\hline sgt $1 b$, rar -10 & $\mathrm{~S}$ & nd & $\mathrm{S}$ & Rsys & $\mathrm{S}$ \\
\hline sgt $1 b /$ rar-10 & $\mathrm{S}$ & nd & $\mathrm{S}$ & Rsys & $\mathrm{S}$ \\
\hline
\end{tabular}

${ }^{a} \mathrm{~S}=$ susceptible but symptomless; $\mathrm{S}+=$ mild symptoms appeared occasionally ( 1 or a few plants over 12 infected) and did not affect plant growth; $\mathrm{S}++=$ an intermediate situation between the two extremes; S+++ = all plants infected developed severe growth defects leading, in most cases, to death at 3 to 4 weeks postinoculation; $\mathrm{Ri}=$ resistance to PPV inoculation; Rsys = resistance to PPV long-distance movement; nd = not determined.

b AteIF(iso) 4E-1 was obtained by insertion of a transposon within the $e I F($ iso) $4 E$ gene (Duprat et al. 2002).

${ }^{c}$ Provided by J. Parker (Max Planck Institute, Cologne, Germany) and coworkers. 
far. Whereas severe symptoms have been observed in Ler in response to infection by PPV-R isolate, only very mild symptoms were observed in the Col- 0 accession (Table 2 and Fig. 1). To determine the number of loci controlling severe symptom development in the Ler accession infected by the PPV-R isolate, we used a recombinant F2 population between Ler and Col-0. Parental and F2 plants were scored for development of symptoms and virus accumulation, as determined by ELISA. The results showed that the ratio of symptomatic versus asymptomatic plants did not fit with simple genetic models, suggesting that several loci are involved in the control of this trait. A total of 62 individuals out of 115 developed symptoms, which
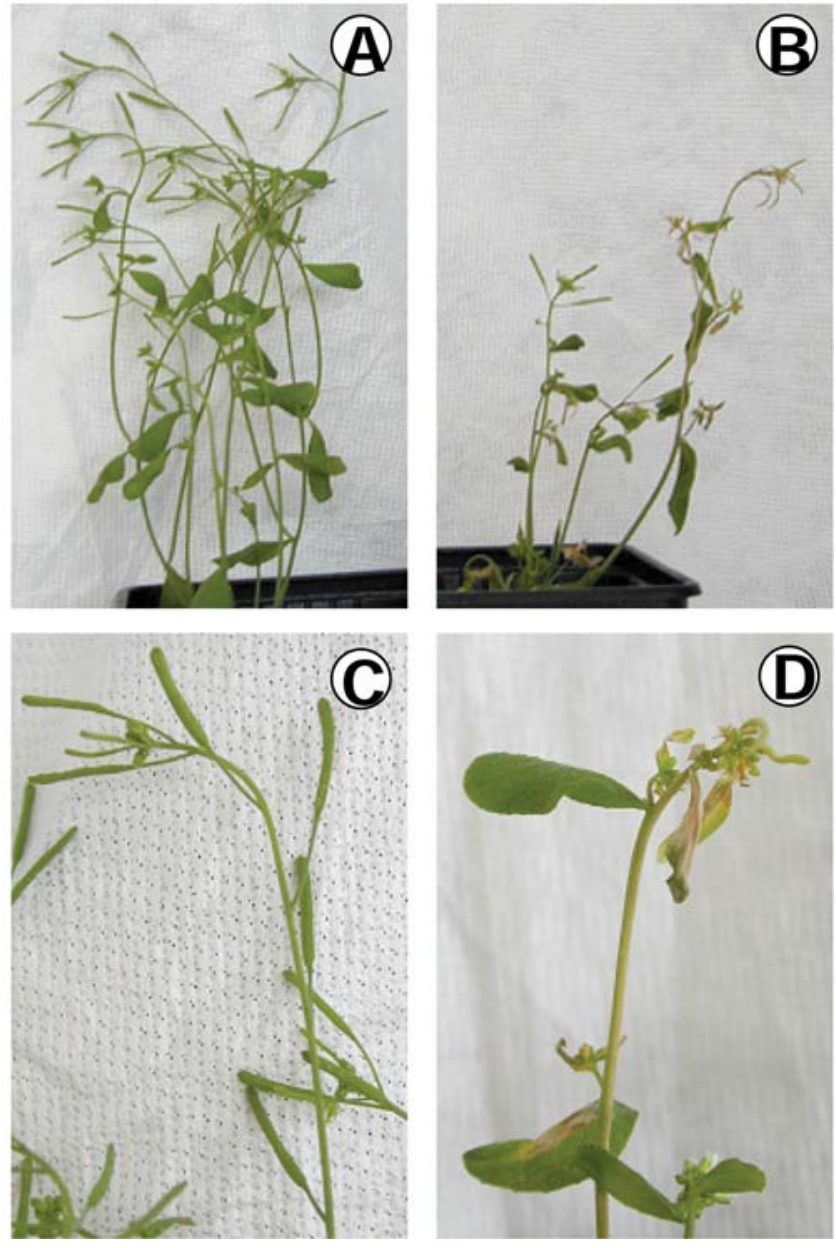

Fig. 1. Symptoms exhibited by Arabidopsis thaliana accession Ler when infected with Plum pox potyvirus (PPV)-R. A, Healthy plant 3 weeks after inoculation with PPV-R. B, Infected Landsberg erecta (Ler) plant with severe symptoms and stunting, 3 weeks after inoculation. C, Close-up of A showing healthy inflorescences. D, Close-up of Ler inflorescences infected with the PPV-R isolate and showing leaf curling and chlorosis and severe inflorescence distortion. is consistent with a 9:7 segregation ratio, indicating that this trait is controlled by at least two loci $(P=0.6134$ to 0.5311 ; Table 2). Some F2 individuals developed more severe symptoms than the Ler parental line; these plants showed severe stunting and died within $21 \mathrm{dpi}$. This observation suggests that the Col- 0 parent might contribute with one or more supplementary genetic factors enhancing or accelerating the severity of the symptoms.

\section{Analysis of local resistance \\ to inoculation by the PPV-SoC isolate.}

The Ri observed during the interaction between PPV-SoC and most ecotypes tested, failed to detect any virus in the inoculated leaves, suggesting either a link with either $R$ gene-mediated resistance pathways or a nonhost passive resistance. The first possibility was evaluated in the Ler accession by analyzing the behavior of available mutant lines affecting two genes identified as essential in $R$ gene-triggered disease resistance, RARl and SGT1 (Austin et al. 2002; Azevedo et al. 2002; Tornero et al. 2002). Table 1 shows that, contrary to the wildtype Ler accession, sgtlb and rarl mutants and the sgt/rarl double mutant supported the local accumulation of the PPVSoC isolate. However, these mutants still failed to support PPV-SoC systemic infection, indicating the existence in these plants of two levels of resistance, one restricting local PPVSoC infection, compromised by the rarl or $s g t l b$ mutations, and the other, independent of these factors, acting to block the long-distance spread of the virus.

\section{Analysis of the resistance to PPV-EA long-distance movement in Col-0.}

Segregation data obtained for resistance to PPV-EA infection in the Col- $0 \times$ Ler F2 population was consistent with a single dominant gene model (79:17 resistant/susceptible, $P=$ 0.098 , for a segregation ratio of $3: 1)$. In A. thaliana, three dominant loci have been shown to confer resistance to the longdistance movement of another potyvirus, TEV, and were designated RTM for restricted TEV movement (Mahajan et al. 1998). Mapping of the resistance trait associated with restriction of PPV-EA systemic spread in the recombinant inbred lines (RIL) of Lister and Dean (1993) allowed the identification of a single region, in the upper part of chromosome 1 in the vicinity of the RTM1 gene (data not shown) (Mahajan et al. 1998). To analyze the possible involvement of the RTM in the resistance to PPVEA, chemically induced rtm mutants (Mahajan et al. 1998; Whitham et al. 1999) were challenged with the PPV-EA isolate (Table 3). In all three mutants, PPV-EA was able to infect uninoculated tissues and was readily detected in cauline leaves and inflorescence tissues. In order to determine whether the $R T M$ loci are also required for restriction of the long-distance movement of other potyviruses, the $\mathrm{rtm}$ mutants were inoculated with the AF199 isolate of Lettuce mosaic virus (LMV), which was previously reported to be unable to systemically invade the Col-0 accession (Revers et al. 2003). Again, restric-

Table 2. Statistical inheritance analysis in selected Arabidopsis-Plum pox potyvirus (PPV) interactions

\begin{tabular}{|c|c|c|c|c|c|}
\hline Arabidopsis F2 populations & PPV isolate & Number tested & Segregation & Genetic determinism & $\chi^{2}(P \text { value })^{a}$ \\
\hline \multicolumn{6}{|c|}{ Symptom intensity (ratio of symptomatic over asymptomatic plants) } \\
\hline Col- $0 \times$ Ler $^{\mathrm{b}}$ & $\mathrm{R}$ & $\begin{array}{l}115 \\
118\end{array}$ & $\begin{array}{l}62: 53 \\
63: 55\end{array}$ & $\begin{array}{l}\text { 9R:7S } \\
\text { 9R:7S }\end{array}$ & $\begin{array}{l}0.6134 \\
0.5311\end{array}$ \\
\hline \multicolumn{6}{|c|}{ Virus accumulation (ratio of resistant over susceptible plants) } \\
\hline Col- $0 \times$ Ler & EA & 96 & $79: 17$ & 3R:1S & 0.0989 \\
\hline Cvi $\times$ Ler & PS & 96 & $17: 79$ & $1 \mathrm{~S}: 3 \mathrm{R}$ & 0.0989 \\
\hline
\end{tabular}

${ }^{a} P$ values calculated for a $\chi^{2}$ of 1 degree of freedom resulted from a chi-square test of fit of the data to two dominant genes (9R:7S), a single dominant gene (3R:1S), and a single recessive gene models (1R:3S). When $P>5 \%$, the hypothesis that the observed ratio of segregation is consistent with the expected ratio cannot be rejected.

b The Col-0 $\times$ Landsberg erecta (Ler) F2 population was tested twice for symptom appearance. 
tion to long-distance movement was found to be abolished in all three rtm mutants (Table 3). As further confirmation of the involvement of the RTM system, a T-DNA insertion knockout (KO) line for RTM2 in the Col-0 background was obtained from the SALK collection, and homozygous mutant plants were selected by PCR on genomic and complementary DNAs. The rtm $2 \mathrm{KO}$ mutant showed no obvious morphological defects, and the chemically induced rtm 2 mutant (Whitham et al. 1999) allowed long-distance movement of PPV-EA and LMVAF199 (Table 3). The results indicated that the resistance of the Col-0 accession to the long-distance movement of several potyvirus isolates, including PPV-EA and LMV-AF199, is conditioned by the RTM genes. In contrast, the Col- 0 acces-

Table 3. Comparison of susceptibility of $\mathrm{rtm}$ Col-0 mutants to infection by three different potyviruses

\begin{tabular}{lccc}
\hline & \multicolumn{3}{c}{ Potyvirus isolate $^{\mathrm{a}}$} \\
\cline { 2 - 4 } Arabidopsis accessions & TEV-GUS $^{\mathrm{b}}$ & PPV-EA & LMV-AF199 $^{-}$ \\
\hline Col-0 & Rsys & Rsys & Rsys \\
$r t m 1-1, r t m 1-2^{\mathrm{b}}$ & $\mathrm{S}$ & $\mathrm{S}$ & $\mathrm{S}$ \\
$r t m 2-1^{\mathrm{b}}$ & $\mathrm{S}$ & $\mathrm{S}$ & $\mathrm{S}$ \\
$r t m 3-1^{\mathrm{b}}$ & nd & $\mathrm{S}$ & $\mathrm{S}$ \\
$r t m 2^{\mathrm{c}}$ & nd & $\mathrm{S}$ & $\mathrm{S}$ \\
\hline
\end{tabular}

${ }^{\mathrm{a}} \mathrm{TEV}=$ Tobacco etch virus, $\mathrm{PPV}=$ Plum pox potyvirus, $\mathrm{LMV}=$ Lettuce mosaic virus; $\mathrm{nd}=$ not determined.

${ }^{b}$ Ethylmethylsulfonate mutants and phenotypes when infected with TEV (Whitham et al. 2000).

${ }^{c}$ T-DNA insertion line (SALK_010448).
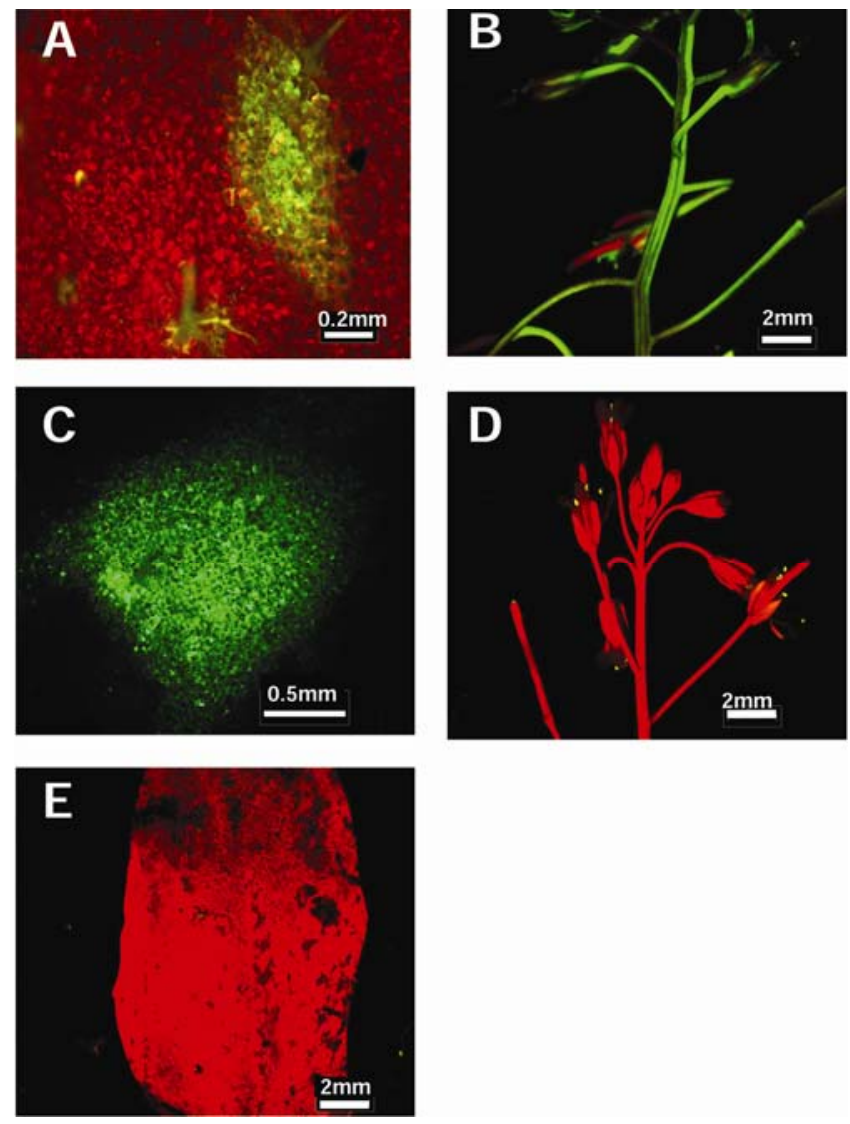

Fig. 2. Green fluorescent protein (GFP)-tagged Plum pox potyvirus (PPV)PS movement is restricted to inoculated leaves of the Cvi-1 accession. Photographs taken under UV light of A, and B, PPV-R GFP and C, and D, PPV-PS GFP in Cvi-1-inoculated (A and C) and -uninoculated (B and D) tissues. E, Control consisting of AteIF(iso) 4 E-1 mutant plants inoculated with PPV-PS GFP. The photographs were taken at 8 (A, C, and E) and 21 (B and D) days postinoculation. sion was found to be fully susceptible to the PPV M and D strains (Table 1), indicating that some PPV isolates are able to overcome RTM resistance or are RTM independent.

\section{Analysis of the resistance}

\section{to PPV-PS long-distance movement in Cvi-1.}

The resistance that confines PPV-PS infection to inoculated leaves in the Cvi-1 accession was analyzed in further detail. PPV-PS replication does not appear to be inhibited, since the virus was detected by RT-PCR or by ELISA at 9 dpi in inoculated rosette leaves (data not shown). The presence of infectious PPV particles was confirmed by successful back-inoculation from Cvi-1-inoculated rosette leaves to Nicotiana benthamiana plants, which developed typical vein clearing and chlorosis PPV symptoms (data not shown). Absence of virus in the upper uninoculated tissues indicated that the PPV-PS long-distance movement was disturbed.

Replication, local movement within the inoculated leaf, and long-distance movement to distal tissues were assessed by inoculation of the Cvi-1 accession with a green fluorescent protein (GFP)-tagged PPV-PS recombinant isolate. Inoculation of

\section{LG1}

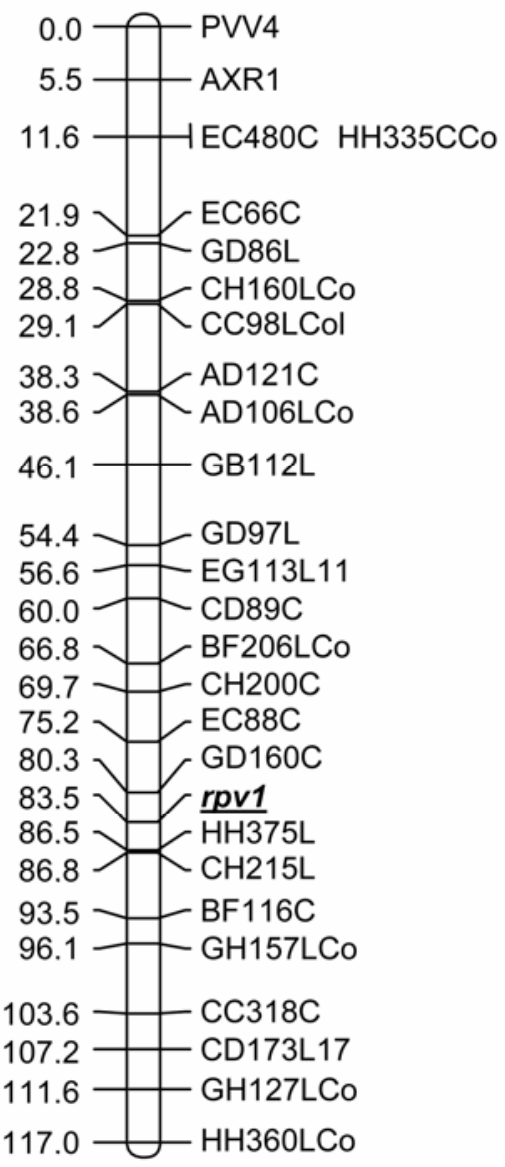

Fig. 3. Map position of $r p v 1$ on chromosome 1 of Arabidopsis thaliana Cvi1 accession. The rpvl (restricted Plum pox virus) locus was mapped as a single gene by MAPMAKER analysis and was positioned between GD160C and $\mathrm{HH} 375 \mathrm{~L}$ on linkage group 1 (LG1). The figure was drawn with MapChart and indicates the genetic distance on the left side (in $\mathrm{cM}$ ), the markers on the right side, and the target locus rpvl in bold and underlined. 
Cvi-1 with a GFP-tagged PPV-R recombinant or inoculation of the AteIF(iso)4E-1 mutant plants served as controls. In the Cvi-1 accession, the GFP-tagged PPV-R isolate replicated within the inoculated leaves (Fig. 2A) and spread systemically into the uninoculated tissues and inflorescences (Fig. 2B). In contrast, the GFP-tagged PPV-PS isolate accumulated only in the Cvi-1 inoculated leaves (Fig. 2C) and GFP fluorescence was never detected in the uninoculated inflorescence tissues (Fig. 2D). In control inoculated leaves of the AteIF(iso)4E-1 mutant, no GFP fluorescence was observed, irrespective of the recombinant PPV isolate used (Fig. 2E).

Genetic analysis of the F2 progeny derived from a cross made between Cvi-1 and Ler (Table 2) showed that restriction of PPV-PS infection in Cvi-1 segregated as a single recessive gene (segregation ratio of $1: 3 ; P=0.098$ ). This Cvi-1 locus was designated as $r p v l$ for "restricted plum pox virus." Since the rpvl resistance is recessive, while that conferred by the RTM genes is dominant, restriction of PPV-PS long-distance movement in Cvi-1 should correspond to a mechanism distinct from the RTM-mediated pathway.

A mapping population of 162 RIL developed from a cross between the Cvi-1 and Ler accessions (Alonso-Blanco et al. 1998) was used to identify the genomic region encompassing $r p v 1$. A single region for the position of $r p v 1$ in the A. thaliana genome was identified with the different statistical procedures assayed. It mapped as a single gene by MAPMAKER analysis or as a single QTL by interval mapping and composite interval mapping (CIM) using MultiQTL analysis. The rpv1 locus was located on chromosome 1 between the GD160C and HH375L markers (Fig. 3) and was recurrent over two different phenotyping scoring data sets (log of the likelihood ratio [LOD] score of 12 by MAPMAKER analysis). One marker in this region, $\mathrm{HH} 375 \mathrm{~L}$, had the strongest correlation seen in the QTL analysis (LOD score of 4.58 by CIM). Interestingly, while the susceptible parental line Ler was asymptomatic when inoculated with the PPV-PS isolate, the ability to develop symptoms in response to PPV segregated as a single gene in the Cvi-1 $\times$ Ler progeny (F2 population and RIL). This factor of symptomatology should be provided by the Cvi-1 accession but was masked in the parental line by the resistance conferred by the rpvl homozygous locus.

Five recombinant viruses constructed between infectious pGPPV-PS and pGPPV-R full-length clones (Sáenz et al. 2000) were used to locate the genetic determinant responsible for breaking the $r p v 1$ resistance by PPV-R. As shown in Figure 4 , the $\mathrm{R} / \mathrm{P}_{2212-3628}$ and $\mathrm{R} / \mathrm{P}_{2212-7677}$ viruses, carrying the $5^{\prime}$ and $3^{\prime}$ ends from PPV-R, were able to systemically spread on Cvi-1 plants, whereas the complementary recombinant viruses, $\mathrm{P} / \mathrm{R}_{2212-3628}$ and $\mathrm{P} / \mathrm{R}_{2212-7677}$, in which the $5^{\prime}$ and $3^{\prime}$ sequences come from PPV-PS, did not move outside of the inoculated

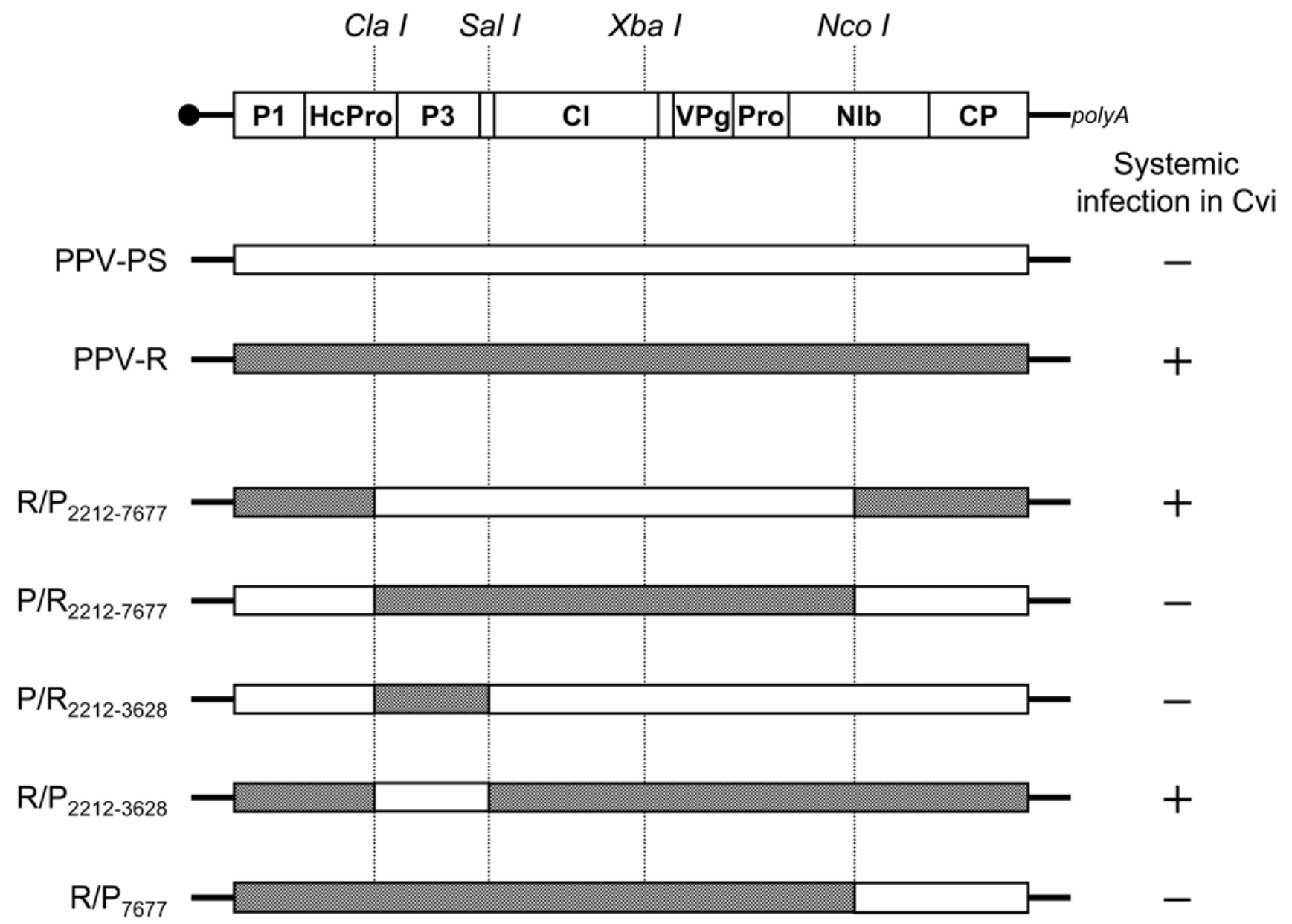

Fig. 4. Schematic representation of the genome of Plum pox potyvirus (PPV) and of the R and PS PPV recombinant viruses tested on the Cvi-1 accession. PPV-PS and PPV-R sequences are shown as open and filled boxes, respectively. Restriction sites used in the cloning are indicated. A genetic map of PPV, indicating the positions of the encoded proteins, is shown at the top of the figure. Infectious clones and recombinants are fully described (Sáenz et al. 2000). The names of the virus proteins are indicated in the genome map at the top of the figure. HcPro is the aphid transmission helper component-proteinase with a gene silencing suppression ability; CI is the cylindrical inclusion protein with a role in cell-to-cell movement and an RNA helicase activity; VPg is linked to the $5^{\prime}$ end of the genome (circle); Pro is the major proteinase responsible for polyprotein processing; NIb is the RNA-dependent RNA polymerase; CP is the capsid protein (Urcuqui-Inchima et al. 2001). 
leaves, indicating that the ability of PPV-R to break the $r p v 1$ resistance should either be located in the first 2,212 nt ([5' noncoding region [NCR], P1, and part of the HcPro coding sequences) or in the $3^{\prime}$ terminal region of the genome (from nt 7,677 to the end, corresponding to the end of the nuclear inclusion polymerase $\mathrm{b}(\mathrm{Nib})$ and capsid protein $[\mathrm{CP}]$ coding sequences, plus the $3^{\prime} \mathrm{NCR}$ ) or that both of these regions are involved. $\mathrm{R} / \mathrm{P}_{7677}$ revealed that the $3^{\prime}$ terminal region from PPV-R is necessary to overcome the $r p v 1$ resistance. However, we cannot yet rule out the possibility of a role of the $5^{\prime}$ part of the PPV-R genome.

\section{DISCUSSION}

The results presented here demonstrate that A. thaliana is a suitable host to search for genetic factors involved in controlling susceptibility or resistance to PPV infection. PPV isolates exhibit very different behavior when infecting various $A$. thaliana accessions, providing a wide panel of infection phenotypes ranging from complete local resistance to full susceptibility, with systemic infection accompanied or not by severe symptoms. A. thaliana is a small herbaceous plant with a short life cycle that has become an excellent model for genetic studies. It is notably different from the usual PPV host plant Prunus spp., but the fact that several PPV strains and isolates infect Arabidopsis plants with different efficiency provides an excellent system to study PPV-plant interactions.

The infection of $A$. thaliana by many viruses has been previously reported. Many other viruses systemically infect Arabidopsis accessions but show mild or no symptoms. A few of them induce severe symptoms in infected organs, such as Turnip crinkle virus (TCV) (Simon et al. 1992) and Turnip mosaic virus (TuMV) (Martin-Martin et al. 1999), but they generally display low variation in the severity of these symptoms. Consequently, limited information is currently available on plant genes that may condition symptom development in a susceptible host. In contrast, the results reported here highlight the existence of wide, isolate- or accession-specific variations in symptom severity in the PPV-Arabidopsis pathosystem. The development of PPV-PS-induced symptoms in a Cvi-1 background appears to be controlled by a single locus, while symptom severity in Ler infected with PPV-R is conditioned by at least two genes. The genetic determinants of symptom development in Ler infected with PPV-R and Bay-0 infected with the PPV-NAT or PS isolates are currently under study, using the Lister and Dean and the Bay- $0 \times$ Shahdara RIL progenies, respectively (Loudet et al. 2002).

Variations in symptom severity may correspond to different processes. In particular, they may reflect variations in the timing or intensity of virus accumulation or, alternatively, may result from differential host behavior under comparable virus accumulation conditions (tolerance). Preliminary results tend to indicate that in the Cvi-1 $\times$ Ler progeny, symptomatic and asymptomatic plants accumulate PPV-PS to essentially similar levels. Some single loci controlling symptom development in $A$. thaliana have been identified by genetic screens of Arabidopsis mutants or accessions (Fujisaki et al. 2004; Lee et al. 1996; Park et al. 2002; Sheng et al. 1998) and, similar to the Cvi-1 $\times$ Ler situation reported here, virus distribution and accumulation were similar in symptomatic and asymptomatic plants; none of these genes has been cloned so far. In contrast, Dardick and associates (2000) showed that, although the Shahdara accession supports rapid accumulation of TMV and develops distinctive disease symptoms, full sensitivity is controlled by at least two genes. One confers rapid virus accumulation, while the other determines the severe symptom phenotype. This second situation could be parallel to the situation observed in Ler inoculated with PPV-R and in which preliminary results indicate that there could be at least a partial correlation between virus accumulation and symptom severity.

Two Ler mutants debilitated for $R$ gene-mediated resistance, rarl and $s g t 1 b$, were susceptible to PPV-SoC, suggesting that the resistance to inoculation of Ler to this isolate is possibly controlled by a dominant $R$ gene. Dominant genes controlling resistance to other viruses in $A$. thaliana have been described: HRT for TCV (Cooley et al. 2000), RCYI for Cucumber mosaic virus (Takahashi et al. 2001), and LLM1 for LMV (Revers et al. 2003). Further analysis of other accessions showing Ri to PPV and other mutants affected in the $R$ pathway will be required to evaluate the generality of the relationship between an Ri phenotype and one or more $R$ genes. Indeed, many components of the $R$-gene signaling pathways are also involved in nonhost resistance independently of $R$ genes.

The RTM mechanism restricting virus long-distance movement was initially described as being specific to TEV (Chisholm et al. 2000; Mahajan et al. 1998; Whitham et al. 1999, 2000). This conclusion was based on the observation that Arabidopsis accessions RTM-restrictive for TEV, such as Col-0 or Ws-2, were fully susceptible to isolates of several potyviruses such as Potato virus $Y$ (PVY), Tobacco vein mottling virus (TVMV), or TuMV. In addition, experiments involving three different isolates of TEV failed to reveal variability in their behavior towards the RTM genes (Whitham et al. 2000). By contrast, the results reported here demonstrate that the long-distance movement of both PPV-EA and LMV-AF199 is restricted by the RTM genes in the Col-0 accession. This interpretation is indirectly supported by the observation that these isolates are able to systemically infect Arabidopsis accessions known to carry naturally permissive $\mathrm{rtm}$ alleles such as C24 or Ler. The RTM-mediated resistance, therefore, appears to have a significantly broader spectrum of action than was initially hypothesized and could even potentially be envisioned as a broadspecificity, Potyvirus-specific, long-distance movement restriction system. In such a hypothesis, potyviruses such as PVY, TVMV, and TuMV, which are able to systemically invade accessions carrying restrictive alleles, such as Col-0, would be interpreted as being able to overcome the RTM-mediated resistance. A similar situation applies to the NAT, PS, and R isolates of PPV, which are able to systemically spread on RTMrestrictive accessions such as Col-0 and Wassilewskija (Ws and Ws-2). Despite the cloning of the RTM1 and RTM2 genes (Chisholm et al. 2000; Whitham et al. 1999, 2000), the one or more mechanisms by which the RTM genes exert their restrictive effect on the potyvirus movement are still a matter of speculation. The discovery that some potyviruses such as PPV are able to overcome this resistance in an isolate-specific fashion opens the way to the identification, through reverse genetics approaches, of one or more viral resistance-breaking determinants. This information should, in turn, help us to understand the functioning of this original resistance system.

Another question that remains open is whether the block of the long-distance movement of RTM-breaking isolates observed in the Kas-1, Shahdara (PPV-R), and Cvi (PPV-PS) accessions is related to the RTM system or represents yet other genetic systems controlling potyviral invasion of $A$. thaliana. In the case of the Cvi-1 accession, however, the inheritance pattern reported here is consistent with a single recessive gene (rpv1), which was mapped away from the known positions of RTM1 and RTM2. Although RTM3 has not yet been cloned, preliminary mapping data indicate that it is located in a different genome position than rpvl (J. C. Carrington, personal communication). Therefore, it appears very unlikely that the rpv1 resistance could be related to the RTM-mediated resistance. Given the recessive nature of the rpvl resistance, the 
most likely hypothesis is that, similar to the eIF4E-mediated resistance, the $R P V$ gene encodes a plant factor strictly required by the virus, in this case for infection of uninoculated tissues. Such a situation would be similar to that reported by Lartey and associates (1998), who described an A. thaliana recessive mutant, vsml, defective for Turnip vein clearing tobamovirus long-distance spread. The preliminary investigations of the rpvl resistance-breaking determinant carried by the PPV-R isolate indicate that it is located either in the Cterminal end of the NIb or in the CP. The results obtained so far do not rule out, however, the possibility that multiple determinants located in either the small genomic region identified, the $5^{\prime}$ part of the PPV genome, or both might be involved in this resistance-breaking phenomenon. The $\mathrm{CP}$ is known to be essential for potyvirus long-distance movement (Carrington et al. 1996; Dolja 1994; Urcuqui-Inchima et al. 2001). Since $R P V I$ is likely to encode a host factor involved in PPV long-distance movement and therefore interacting, directly or indirectly, with viral proteins involved in this process, it seems reasonable to hypothesize that $\mathrm{CP}$ is the viral resistance-breaking determinant. So far, very little is known about plant factors contributing to viral long-distance movement. The positional cloning of the $r p v l$ gene, which is currently underway in our laboratory, should provide original information on this largely unknown process of the potyvirus infectious cycle.

One key question that will remain once Arabidopsis resistance and susceptibility factors to PPV infection are identified is whether this new knowledge will be transferable to other pathosystems and, in particular, to its natural Prunus hosts. Because of the limited number of proteins encoded by the pathogen, the virus completely depends on the host factor to complete its life cycle. Studying recessive resistance genes provides a good opportunity to reveal host factors required for susceptibility. Indeed, results obtained with eIF4E and its isoform (Decroocq et al. 2005) suggest that searching for recessive genes that condition critical steps of the potyvirus infectious cycle allow the identification of key factors that are required for PPV infection, both in its herbaceous and perennial hosts.

\section{MATERIALS AND METHODS}

\section{Plant and virus materials.}

All plants were grown under greenhouse conditions. Initial seed stocks were obtained from the Nottingham Arabidopsis Stock Centre (Loughborough, U.K.) or from the Institut National de la Recherche Agronomique (INRA) Versailles collection. Each accession was grown and self-pollinated for one or two generations before screening. PPV isolates were propagated on N. benthamiana prior to Arabidopsis inoculation. The LMV isolate LMV-AF199 described by Krause-Sakate and associates (2002) was routinely propagated on the lettuce cultivar Trocadéro.

The Arabidopsis RTM2 T-DNA insertion line in the Col-0 background (SALK_010448) was obtained from the Nottingham Arabidopsis Stock Centre. Insertion mutant information was obtained from the Salk Institute Genomic Analysis Laboratory website. The T-DNA insertion site was confirmed by PCR, using the T-DNA left border-specific primer LBa1 5'TGGTTCACGTAGTGGGCCATCG-3' and RTM2-specific primers LP10448 5'-TGATGACCTGAGACAAAAGAAGAG A-3' and RP10448 5'-TTCTTGAAGCTTCTTTGCCGC-3'.

Construction of pGPPV-R, pGPPV-PS, and the corresponding recombinant clones was described previously (Sáenz et al. 2000). The recombinant GFP-tagged PPV isolates used in this work derived from the PPV-R cDNA clone pICPPV-NK-
GFP (Fernandez-Fernandez et al. 2001) and from the PPV-PS cDNA clone pGPPVPS-RnGFPs (B. Salvador, P. Sáenz, J. B. Quiot, C. Simón-Mateo, and J. A. García, unpublished results).

\section{PPV inoculation procedure.}

Before inoculation, inflorescences of 4- to 6-week-old Arabidopsis plants were removed. Four plants of each accession were hand-inoculated twice, two days apart, on the upper side of three rosette leaves. Inoculum was prepared by homogenizing infected $N$. benthamiana leaves with three volumes of cold citrate buffer $\left(\mathrm{Na}_{3}\right.$ Citrate $0.05 \mathrm{M}$, EDTA $0.5 \mathrm{mM}$, diethyldithiocarbamic acid $0.02 \mathrm{M}, \mathrm{pH} 7.8$ ). After each inoculation, plants were rinsed with water and were maintained in as S3 level containment greenhouse. Samples of inoculated leaves and new inflorescences were collected $9 \mathrm{dpi}$, and inflorescence tissues were collected again at $21 \mathrm{dpi}$. Additional sampling was also initially performed at $30 \mathrm{dpi}$, but since this sampling time did not provide any additional information, this strategy was not continued in later experiments (data not shown). For infection with the PPV-R/PPV-PS chimeras, Arabidopsis plants were inoculated with fresh sap from $N$. clevelandii plants infected with progeny virus derived from RNA obtained by in vitro transcription of the corresponding recombinant plasmids (Sáenz et al. 2000).

\section{PPV detection.}

PPV replication in inoculated rosette leaves was assayed by RT-PCR using the P1 and P2 primers (Wetzel et al. 1991b). Total RNA was prepared following the method of Bertheau and associates (1998). For RT-PCR reactions, $2.5 \mu \mathrm{l}$ of total RNA were added to $22.5 \mu \mathrm{l}$ of a reaction mixture (TrisHCl, $\mathrm{pH} \mathrm{9,10}$ $\mathrm{mM}, \mathrm{KCl} 50 \mathrm{mM}$, bovine serum albumin $0.2 \mathrm{mg} / \mathrm{ml}$, Triton $\mathrm{X} 1000.3 \%, \mathrm{MgCl}_{2} 1.5 \mathrm{mM}$, dNTP $0.25 \mathrm{mM}$, each primer 1 $\mu \mathrm{M}$, ABgene Reverse-iTreverse transcriptase blend $1.5 \mathrm{U}$, Invitrogen $\mathrm{Taq}$ polymerase $0.5 \mathrm{U}$ ). A reverse transcription of 15 min at $42^{\circ} \mathrm{C}$ was followed by 40 cycles of denaturation at $92^{\circ} \mathrm{C}$ for $40 \mathrm{~s}$, annealing at $56^{\circ} \mathrm{C}$ for $40 \mathrm{~s}$, and extension at $72^{\circ} \mathrm{C}$ for $40 \mathrm{~s}$. Infection on uninoculated inflorescence tissue at 9 and 21 dpi was assayed by double antibody sandwich-ELISA using PPV capsid antibody (M+D antibody, LCA Laboratory, Blanquefort, France) and, if needed, was confirmed by RT-PCR. Symptoms were scored visually from 15 to $21 \mathrm{dpi}$.

Three replicate measurements were made for each accession. In each replicate, leaves and inflorescences were collected from four distinct plants of the same accession. F2 populations, RIL, and mutants were tested similarly to the parental lines. The AteIF(iso)4E-1 transposon-disrupted mutant line (Duprat et al. 2002; Lellis et al. 2002) was used as a negative control and, at the time of sampling 9 days after inoculation, the inoculum was detected neither by ELISA nor RT-PCR on inoculated leaves of this line.

\section{Mapping of the rpv1 locus.}

The mapping population consisted of 162 RIL developed from a cross between the Cape Verde Islands (Cvi-1) and Ler accessions (Alonso-Blanco et al. 1998). The genetic linkage map used contains 99 amplification and restriction fragment length polymorphism markers. The chromosomal location of the $r p v 1$ locus was determined using the MAPMAKER program version 3.0 (Lander et al. 1987), and markers were positioned on the linkage map at a minimum LOD $=3$. The genetic map was drawn with MapChart software (Voorrips 2002). To confirm the occurrence of one or more genomic regions, a quantitative trait analysis using MultiQTL software was also performed (Korol et al. 2001). Information on the DNA markers was obtained from the Arabidopsis Information Resource (TAIR) database and the European "Natural" cooperative database. 
Fluorescence detection of GFP-tagged PPV.

Cvi-1 plants 4 to 5 weeks old were mechanically inoculated with GFP-tagged PPV isolates on the tip of four to five rosette leaves as described above. Green fluorescence was scored on inoculated leaves 4 to $14 \mathrm{dpi}$ and at 19 to $21 \mathrm{dpi}$ in uninoculated organs. Fluorescence was observed using a fluorescence stereomicroscope MZFL III (Leica Microsystems, Wetzlar, Germany), equipped with a filter with an excitation window at $470 / 40 \mathrm{~nm}$ for GFP3 and B filters, a barrier filter at 525/50 nm for GFP3, and $515 \mathrm{~nm}$ for the B filter.

\section{NOTE ADDED IN PROOF}

After partial sequencing, the authors noticed that the PS isolate maintained on $N$. benthamiana in Bordeaux and used initially to screen $A$. thaliana accessions (Table 1) does not correspond to the PS sequence used to generate the infectious GFPtagged PS PPV and PS/R recombinants (Sáenz et al. 2000). However, data presented in this paper are still relevant since both isolates were compared on the Cvi-1 and Ler accessions and displayed similar behavior (resistance versus susceptibility).

\section{ACKNOWLEDGMENTS}

We thank G. Labonne, INRA Montpellier, for the PPV-SoC strain. We are grateful to M. Koornneef (Wageningen Agricultural University, Netherlands) for the Cvi $\times$ Ler F1 seeds, M. Grelon (INRA Versailles) for the Col- $0 \times$ Ler F2 population, J. Carrington (Oregon State University, USA) for the rtm mutants and for unpublished information of the preliminary mapping of the RTM3 gene, J. Parker (Max Planck Institute, Cologne, Germany) for the sgt and rar mutants. We thank T. Mauduit and $\mathrm{M}$. Roncoroni for the production and maintenance of the Arabidopsis plants, L. Svanella-Dumas for computer work, and W. Kieffer for technical assistance. Experiments were carried out in compliance with the current French and European guidelines concerning quarantine and recombinant pathogens. This work was supported in part by grants from INRA's 'Jeune Equipe' program and from the Etablissement Public Régional Aquitaine (contract number 20000307004). J. M. Alamillo and J. A. García were supported by grant BIO2004-02687 from the Spanish Ministerio de Educacion y Ciencia.

\section{LITERATURE CITED}

Alonso-Blanco, C., Peeters, A. J., Koornneef, M., Lister, C., Dean, C., van den Bosch, N., Pot, J., and Kuiper, M. T. 1998. Development of an AFLP based linkage map of Ler, Col and Cvi Arabidopsis thaliana ecotypes and construction of a Ler/Cvi recombinant inbred line population. Plant J. 14:259-271.

Austin, M. J., Muskett, P., Kahn, K., Feys, B. J., Jones, J. D. G., and Parker, J. E. 2002. Regulatory role of $S G T 1$ in early $R$ gene-mediated plant defenses. Science 295:2077-2080.

Azevedo, C., Sadanandom, A., Kitagawa, K., Freialdenhoven, A., Shirasu, K., and Schulze-Lefert, P. 2002. The RAR1 interactor SGT1, an essential component of $R$ gene-triggered disease resistance. Science 295:2073-2076.

Bertheau, Y., Frechon, D., Toth, I. K., and Hyman, L. J. 1998. DNA amplification by polymerase chain reaction (PCR). Pages 39-59 in: Methods for the Detection and Quantification of Erwinia carotovora subsp. atroseptica on Potatoes. M. C. M. Perombelon, and J. M. Van der Wolff (eds). Scottish Crop Research Institute, Invergowrie, Dundee, Scotland.

Candresse, T., Cambra, M., Dallot, S., Lanneau, M., Asensio, M., Gorris, M. T., Revers, F., Macquaire, G., Olmos, A., Boscia, D., Quiot, J. B., and Dunez, J. 1998. Comparison of monoclonal antibodies and polymerase chain reaction assays for the typing of isolates belonging to the D and M serotypes of Plum pox potyvirus. Phytopathology 88:198-204.

Carrington, J. C., Kasschan, K. D., Mahajun, S. K., and Schaad, M. C. 1996. Cell-to-cell and long distance transport of viruses in plants. Plant Cell 8:1669-1681.

Chisholm, S. T., Mahajan, S. K., Whitham, S. A., Yamamoto, M. L., and Carrington, J. C. 2000. Cloning of the Arabidopsis RTM1 gene, which controls restriction of long-distance movement of Tobacco etch virus. Proc. Natl. Acad. Sci. U.S.A. 97:489-494.

Cooley, M. B., Pathirana, S., Wu, H. J., Kachroo, P., and Klessig, D. F. 2000. Members of the Arabidopsis HRT/RPP8 family of resistance genes confer resistance to both viral and oomycete pathogens. Plant Cell 12:663-676.

Crescenzi, A., D’Aquino, L., Comes, S., Nuzzaci, M., Piazzola, P., Boscia, D., and Hadidi, A. 1997. Characterisation of the sweet cherry isolate of plum pox potyvirus. Plant Dis. 81:711-714.

Dardick, C. D., Golem, S., and Culver, J. N. 2000. Susceptibility and symptom development in Arabidopsis thaliana to Tobacco mosaic virus is influenced by virus cell-to-cell movement. Mol. Plant-Microbe Interact. 13:1139-1144.

Decroocq, V., Foulongne, M., Lambert, P., Le Gall, O., Mantin, C., Pascal, T., Schurdi-Levraud, V., and Kervella, J. 2005. Analogues of virus resistance genes map to QTLs for resistance to sharka disease in Prunus davidiana. Mol. Genet. Gen. 272:680-689.

Dolja, V. V. 1994. Distinct functions of capsid protein in assembly and movement of Tobacco etch potyvirus in plants. EMBO (Eur. Mol. Biol. Organ.) J. 13:1482-1491.

Duprat, A., Caranta, C., Revers, F., Menand, B., Browning, K. S., and Robaglia, C. 2002. The Arabidopsis eukaryotic initiation factor (iso)4E is dispensable for plant growth but required for susceptibility to potyviruses. Plant J. 32:927-934.

Fernandez-Fernandez, M. R., Mourino, M., Rivera, J., Rodriguez, F. Plana-Duran, J., and Garcia, J. A. 2001. Protection of rabbits against rabbit hemorrhagic disease virus by immunization with the VP60 protein expressed in plants with a potyvirus-based vector. Virology 280:283-291.

Fujisaki, K., Hagihara, F., Azukawa, Y., Kaido, M., Okuno, T., and Mise, K. 2004. Identification and characterization of the SSB1 locus involved in symptom development by Spring beauty latent virus infection in Arabidopsis thaliana. Mol. Plant-Microbe Interact. 17:967-975.

Gao, Z., Johansen, E., Eyers, S., Thomas, C. L., Noel Ellis, T. H., and Maule, A. J. 2004. The potyvirus recessive resistance gene, $s b m 1$, identifies a novel role for translation initiation factor eIF4E in cell-to-cell trafficking. Plant J. 40:376-385.

James, D., and Varga, A. 2005. Nucleotide sequence analysis of Plum pox virus isolate W3174: Evidence of a new strain. Virus R. 110:143-150.

Kang, B. C., Yeam, I., Frantz, J. D., Murphy, J. F., and Jahn, M. M. 2005. The pvrl locus in Capsicum encodes a translation initiation factor eIF4E that interacts with Tobacco etch virus VPg. Plant J. 42:392-405.

Korol, A. B., Ronin, Y. I., Itskovich, A. M., Peng, J., and Nevo, E. 2001. Enhanced efficiency of quantitative trait loci mapping analysis based on multivariate complexes of quantitative traits. Genetics 157:1789-1803.

Krause-Sakate, R., Le Gall, O., Fakhfakh, H., Peypelut, M., Marrakchi, M., Varveri, C., Pavan, M. A., Souche, S., Lot, H., Zerbini, F. M., and Candresse, T. 2002. Molecular characterization of Lettuce mosaic virus field isolates reveals a distinct and widespread type of resistance-breaking isolate: LMV-Most. Phytopathology 92:563-572.

Lander, E. S., Green, P., Abrahamson, J., Barlow, A., Daly, M. J., Lincoln, S. E., and Newburg, L. 1987. MAPMAKER: An interactive computer package for constructing primary genetic linkage maps of experimental and natural populations. Genomics 1:174-178.

Lartey, R. T., Ghoshroy, S., and Citovsky, V. 1998. Identification of an Arabidopsis thaliana mutation $(\mathrm{vsm} 1)$ that restricts systemic movement of tobamoviruses. Mol. Plant-Microbe Interact. 11:706-709.

Lee, J. M., Hartman, G. L., Domier, L. L., and Bent, A. F. 1996. Identification and map location of TTR1, a single locus in Arabidopsis thaliana that confers tolerance to Tobacco ringspot nepovirus. Mol. PlantMicrobe Interact. 9:729-735.

Lellis, A. D., Kasschau, K. D., Whitham, S. A., and Carrington, J. C. 2002. Loss-of-susceptibility mutants of Arabidopsis thaliana reveal an essential role for eIF(iso)4E during potyvirus infection. Curr. Biol. 12:10461051 .

Lister, C., and Dean, C. 1993. Recombinant inbred lines for mapping RFLP and phenotypic markers in Arabidopsis thaliana. Plant J. 4:745750 .

Loudet, O., Chaillou, S., Camilleri, C., Bouchez, D., and Daniel-Vedele, F. 2002. Bay- $0 \times$ Shahdara recombinant inbred line population: A powerful tool for the genetic dissection of complex traits in Arabidopsis. Theor. Appl. Genet. 104:1173-1184.

Mahajan, S. K., Chisholm, S. T., Whitham, S. A., and Carrington, J. C. 1998. Identification and characterization of a locus (RTM1) that restricts long-distance movement of Tobacco etch virus in Arabidopsis thaliana. Plant J. 14:177-186.

Maiss, E., Timpe, U., Brisske, A., Jelkmann, W., Casper, R., Himmler, G., Mattanovich, D., and Katinger, H. W. D. 1989. The complete nucleotide sequence of Plum pox virus RNA. J. Gen. Virol. 70:513-524.

Martin-Martin, A., Cabrera y Poch, H. L., Martinez-Herrera, D., and Ponz, F. 1999. Resistances to turnip mosaic potyvirus in Arabidopsis thaliana. Mol. Plant-Microbe Interact. 12:1016-1021.

Nemchinov, L., and Hadidi, A. 1996. Characterisation of the sour cherry strain of plum pox virus. Phytopath. 86:575-580. 
Nicaise, V., German-Retana, S., Sanjuan, R., Dubrana, M. P., Mazier, M., Maisonneuve, B., Candresse, T., Caranta, C., and Le Gall, O. 2003. The eukaryotic translation initiation factor $4 \mathrm{E}$ controls lettuce susceptibility to the potyvirus Lettuce mosaic virus. Plant Physiol. 132:1272-1282.

Park, S., Hur, J., Park, J., Lee, S., Lee, T., Chang, M., Davis, K. R., Kim, J., and Lee, S. 2002. Identification of a tolerant locus on Arabidopsis thaliana to hypervirulent Beet curly top virus $\mathrm{CFH}$ strain. Mol. Cells 13:252-258.

Revers, F., Guiraud, T., Houvenaghel, M. C., Mauduit, T., Le Gall, O., and Candresse, T. 2003. Multiple resistance phenotypes to Lettuce mosaic virus among Arabidopsis thaliana accessions. Mol. Plant-Microbe Interact. 16:608-616.

Riechmann, J. L., Lain, S., and Garcia, J. A. 1990. Infectious in vitro transcripts from a plum pox potyvirus cDNA clone. Virology 177:710-716.

Ruffel, S., Dussault, M. H., Palloix, A., Moury, B., Bendahmane, A., Robaglia, C., and Caranta, C. 2002. A natural recessive resistance gene against potato virus $\mathrm{Y}$ in pepper corresponds to the eukaryotic initiation factor 4E (eIF4E). Plant J. 32:1067-1075.

Sáenz, P., Cervera, M. T., Dallot, S., Quiot, L., Quiot, J. B., Riechmann, J. L., and García, J. A. 2000. Identification of a pathogenicity determinant of Plum pox virus in the sequence encoding the C-terminal region of protein P3+6K1. J. Gen. Virol. 81:557-566.

Sheng, J., Lartey, R., Ghoshroy, S., and Citovsky, V. 1998. An Arabidopsis thaliana mutant with virus-inducible phenotype. Virology 249:119-128.

Simon, A. E., Li, X. H., Lew, J. E., Stange, R., Zhang, C. X., Polacco, M., and Carpenter, C. D. 1992. Susceptibility of resistance of Arabidopsis thaliana to Turnip crinkle virus. Mol. Plant-Microbe Interact. 5:496503.

Stein, N., Perovic, D., Kumlehn, J., Pellio, B., Stracke, S., Streng, S., Ordon, F., and Graner, A. 2005. The eukaryotic translation initiation factor $4 \mathrm{E}$ confers multiallelic recessive Bymovirus resistance in Hordeum vulgare (L.). Plant J. 42:912-922.

Takahashi, H., Suzuki, M., Natsuaki, K., Shigyo, T., Hino, K., Teraoka, T., Hosokawa, D., and Ehara, Y. 2001. Mapping the virus and host genes involved in the resistance response in cucumber mosaic virus-infected Arabidopsis thaliana. Plant Cell Physiol. 42:340-347.

Tornero, P., Merritt, P., Sadanandom, A., Shirasu, K., Innes, R. W., and Dangl, J. L. 2002. RAR1 and NDR1 contribute quantitatively to disease resistance in Arabidopsis, and their relative contributions are dependent on the $R$ gene assayed. Plant Cell 14:1005-1015.
Urcuqui-Inchima, S., Haenni, A.-L., and Bernardi, F. 2001. Potyvirus proteins: A wealth of functions. Virus Res. 74:157-175.

Voorrips, R. E. 2002. MapChart: Software for the graphical presentation of linkage maps and QTLs. J. Hered. 93:77-78.

Wetzel, T., Candresse, T., Ravelonandro, M., Delbos, R. P., Mazyad, H., Aboul-Ata, A. A., and Dunez, J. 1991a. Nucleotide sequence of the 3'terminal region of the RNA of the El Amar strain of plum pox potyvirus. J. Gen. Virol. 72:1741-1746.

Wetzel, T., Candresse, T., Ravelonandro, M., and Dunez, J. 1991b. A polymerase chain reaction assay adapted to Plum pox potyvirus detection. $\mathrm{J}$. Virol. Methods 33:355-365.

Whitham, S. A., Yamamoto, M. L., and Carrington, J. C. 1999. Selectable viruses and altered susceptibility mutants in Arabidopsis thaliana. Proc. Natl. Acad. Sci. U.S.A. 96:772-777.

Whitham, S. A., Anderberg, R. J., Chisholm, S. T., and Carrington, J. C. 2000. Arabidopsis RTM 2 gene is necessary for specific restriction of tobacco etch virus and encodes an unusual small heat shock-like protein Plant Cell 12:569-582.

Yamanaka, T., Ohta, T., Takahashi, M., Meshi, T., Schmidt, R., Dean, C., Naito, S., and Ishikawa, M. 2000. TOM1, an Arabidopsis gene required for efficient multiplication of a tobamovirus, encodes a putative transmembrane protein. Proc. Natl. Acad. Sci. U.S.A. 97:10107-10112.

Yamanaka, T., Imai, T., Satoh, R., Kawashima, A., Takahashi, M., Tomita, K., Kubota, K., Meshi, T., Naito, S., and Ishikawa, M. 2002. Complete inhibition of tobamovirus multiplication by simultaneous mutations in two homologous host genes. J. Virol. 76:2491-2497.

\section{AUTHOR-RECOMMENDED INTERNET RESOURCES}

The European "Natural" cooperative database: www.dpw.wau.nl/natural/resources/populations.htm

The INRA Versailles website: dbsgap.versailles.inra.fr/publiclines MAPMAKER software: www-genome.wi.mit.edu/genome_software MultiQTL software: esti.haifa.ac.il/ poptheor and www.multiqtl.com The Nottingham Arabidopsis Stock Center: nasc.life.nott.ac.uk United States Department of Agriculture public health security and bioterrorism website: www.aphis.usda.gov/ppq/permits/agr_bioterrorism The Salk Institute Genomic Analysis Laboratory website: signal.salk.edu TAIR database: www.arabidopsis.org 